\title{
ANÁLISE SÓCIO-HISTÓRICA DE CONSTITUIÇÃO DA CIDADE DE BOGOTÁ/COLÔMBIA E O LUGAR DAS MULHERES EM SITUAÇÃO DE RUA
}

\section{Anyi Paola Munoz Umaña' \\ Leana Oliveira Freitas ${ }^{2}$}

Resumo: Este artigo tem o objetivo primordial de revisar o processo sóciohistórico de constituição de Bogotá (Colômbia), não a partir de generalidades, mas de especificidades e descontinuidades de sua configuração, tentando revelar, neste percurso, a cidade da negação, da invisibilidade, da interdição, enfim, da população em situação de rua e, particularmente, das mulheres atingidas por este fenômeno. Apresentam-se considerações gerais da formação de Bogotá e seus efeitos na produção das relações sociais de raça, classe e gênero que demarcam o contexto histórico do fenômeno, em diálogo com o debate teórico da construção do espaço urbanizado na América Latina. Palavras-chave: Cidade; população em situação de rua; interseccionalidade.

Abstract: This article reviews the historical process of the constitution of Bogotá in Colombia, being based not from generalities but from particularities and discontinuities of its configuration, in order to reveal a city of negation, invisibility and censorship, particularly regarding homeless people and women. General considerations on the formation of Bogotá are presented together with their effects on the production of social relations of race, class and gender that mark the historical context of the phenomenon dialogically with the theoretical debate on the construction of urbanized space in Latin America.

Keywords: City; homeless population; intersectionality.

\section{Introdução}

Este texto está baseado na pesquisa de mestrado Mulheres, rua e politica social: contradições, disputas e violências no uso do espaço público, em desenvolvimento no Programa de Pós-Graduação em Política Social pela Universidade Federal de Mato Grosso, que se encontra em fase de conclusão.

\footnotetext{
1 Mestranda no Programa de Pós-Graduação em Política Social da Universidade Federal de Mato Grosso, Brasil. E-mail: apmunozu@unal.edu.co. Orcid: 0000-0002-2704-0550

2 Professora do Programa de Pós-Graduação em Política Social e do Departamento de Serviço Social da Universidade Federal de Mato Grosso, Brasil. E-mail: leanaof@uol.com.br. Orcid:_0000-0001-9477-6560
} 
Inscreve-se no conjunto de reflexões contidas no primeiro capítulo da dissertação, cujo objetivo é contextualizar histórica e territorialmente como se configura a cidade de Bogotá e, nela a realidade da população em situação de rua em geral e das mulheres atingidas por este fenômeno em particular, colocando as tensões envolvidas na distribuição do espaço da rua em termos das relações sociais de classe, raça e gênero.

Sobre a cidade, ao se reconhecer o espaço como sinônimo de território, admite-se que sua produção vai além da mera produção física. Trata-se de um processo marcado por tensões econômicas nas quais coexistem interesses conflitantes, resultantes da luta de classe (CASTELLS, 1986; LEFEBVRE, 1978). Para além dessas determinações, a partir de uma perspectiva interseccional, baseada nas contribuições de Kimberlé Crenshaw (2002) e Silvia Federici (2017), na produção da cidade disputam-se, ainda, tensões de gênero e de raça, consolidadas na distribuição desigual do espaço onde se cerceia o direito à cidade para determinados segmentos sociais, nos quais se encontram a população em situação de rua.

Assim, no esforço de construir análises orientadas pelo materialismo histórico e compreendendo que a realidade da questão urbana responde a diferentes singularidades, serão apresentadas neste texto algumas reflexões da configuração histórica da cidade de Bogotá, em diálogo com a realidade latino-americana. Entende-se que esta história esteve marcada por relações de dependência, consolidadas no processo de colonização, como forma de sujeição entre várias formações sociais a partir de sua configuração política, cultural e econômica, em que se constituem contornos específicos de produção social do espaço.

Finalmente, espera-se situar no percurso as condições históricas que pautaram a produção do fenômeno da população em situação de rua, com o fim de estabelecer uma definição aproximada desta realidade, contribuindo para uma análise situada e interseccional das relações sócio-históricas envolvidas na disputa pelo espaço da rua.

\section{A cidade: breve contexto sócio-histórico de constituição de Bogotá, Colômbia}

Bogotá é uma cidade localizada no altiplano da cordilheira dos Andes. Por sua geografia e condições climáticas de altitude, foi considerada espaço propício para a adaptação dos colonizadores espanhóis que começaram a chegar à região no ano 1535. Era um território ocupado por comunidades indígenas Muíscas, que, por sua proximidade com 
diferentes fontes de água e pela fertilidade do solo, tinham na agricultura sua atividade econômica principal.

A organização do espaço na comunidade Muísca, segundo os poucos registros encontrados e construídos a partir de visões eurocêntricas nas crônicas dos frades, se caracterizava por comunidades dispersas por todas as partes e, geralmente, erguidas ao lado das lavouras, formando um conjunto pitoresco e desordenado, sem qualquer planificação (MELO, 2001). Porém as formas de organização que existiam antes da cidade colonial não podem ser definidas a partir de parâmetros ocidentais, ainda que muitos registros históricos europeus tentem estabelecer comparações em prejuízo ao estilo de vida dos povos indígenas da América Latina.

No modelo de cidade ocidental trazido pela colonização, os processos de participação coletiva do território e as práticas de trabalho dos Muíscas foram substituídos abruptamente pelo estilo de vida espanhol. $\bigcirc$ espaço circular no qual se organizavam as práticas indígenas foi substituído pelo espaço quadricular, ocorrendo, por consequência, a separação das atividades agricolas da cidade, aprofundando, assim, a divisão social do trabaIho, própria da configuração da cidade ocidental (ROBLEDO GÓMEZ; RODRIGUEZ SANTANA, 2008).

Nas formações sociais pré-coloniais não se demarcavam divisões individuais na distribuição do solo urbano. É com a colonização que os modelos estéticos das propriedades se fecham, a praça cimenta-se como o espaço privilegiado para o desenvolvimento da "vida pública", enquanto a casa encerra a intimidade.

Em consequência, a emergente propriedade privada se converteu aos poucos em meio para medir o lugar da pessoa na sociedade e na cidade. De acordo com o quanto cada um pudesse acumular, determinou-se o controle social, formalizando-se assim a exploração do território e de seus povos. Esta distribuição social da cidade colonial, como reafirmação constante da autoridade dos espanhóis sobre o território, estruturou as bases das relações de poder que pautariam a disputa pelo espaço urbano em Bogotá. Assim, "os conquistadores foram, até 1590, os únicos aos quais podia outorgar-lhes títulos de propriedade da terra" (FORERO, 2016, p. 41, tradução nossa). Processo que esteve, desde o começo, atravessado pelos atributos de classe, gênero e étnico-raciais, sendo um privilégio somente dos homens brancos colonizadores.

Certamente, a colonização representou a substituição da figura dos cacicazgos, própria da organização Muísca, por um sistema de tributos e 
encomenda que concedia aos proprietários da terra direitos sobre o trabalho imposto e forçado dos povos indígenas, o qual vigorou durante os séculos $\mathrm{XVI}$ e XVII. Isto impactou todas as esferas da vida social como estratégia que permitiu a acumulação de certos setores sociais, os quais terminavam "abandonando o exercício das atividades produtivas, dedicando-se, exclusivamente, à tarefa da dominação, como guerreiros, sacerdotes, juízes, administradores, tornando-se, desta maneira, classe dominante" (SINGER, 1998, p. 14). Contudo a consolidação dessas elites se apoiou em estratégias para garantir a extração de excedente alimentar, privilegiando a figura do latifúndio, assegurando a acumulação da propriedade privada por meio de práticas atribuídas socialmente ao âmbito privado: alianças matrimoniais e familiares.

A discussão sobre os efeitos do matrimônio na vida das mulheres é desenvolvida a partir de reflexões feministas que indagam como se tem construído a relação das esferas pública e privada sob uma perspectiva crítica que contemple, além da estrutura de dominação de classe ou raça, as formas de opressão que existem contra as mulheres, respaldadas na organização sexual da vida.

Nessa perspectiva, Carole Pateman (1993), por meio do que denomina como contrato sexual, discute o direito político como expressão do direito patriarcal e afirma que, antes de se estabelecer qualquer tipo de acordo social, foi estabelecido um acordo sexual por meio do contrato matrimonial no qual a propriedade privada, como elemento básico e condição para participar do contrato social e majoritariamente relacionado aos bens materiais, adquire outros elementos e se torna a propriedade sobre determinados corpos.

Segundo essa premissa, no contrato social defendido pelos contratualistas, a origem da esfera pública e, com ela, a da cidade é exclusividade dos homens brancos e burgueses. As mulheres, por sua vez, encontram-se em estado de sujeição imposta pelo contrato sexual, e aquilo que, a princípio, parecia ter origem na esfera do privado, vincula-se à dimensão pública. Como esclarece Pateman (1993), a gênese da esfera pública é explicita, mas a da esfera privada segue sendo uma incógnita. $\bigcirc$ patriarcado não é puramente familiar, está localizado além da esfera privada, de modo que o contrato original cria a sociedade civil patriarcal em sua totalidade.

Além disso, o contrato sexual funciona como uma "peneira" que filtra e mantém hierarquias sociais. Na cidade colonial de Bogotá, por exemplo, os matrimônios eram celebrados entre pessoas do mesmo status social e pertencimento étnico/racial. Esta prática se consolida com maior força nos séculos 
posteriores, em que o contrato matrimonial funcionava como forma de apropriação dos corpos das mulheres, supostamente exclusiva dos vínculos privados, estimulando ainda intercâmbios entre famílias da mesma condição social para a extensão do poder territorial masculino branco sobre o espaço público.

A segregação, característica da propriedade privada, evidente nas formas de associação privilegiadas por meio do matrimônio, é revelada nas reflexões realizadas pela pesquisadora Daisy Rípodas (1977), sobre o matrimônio das mulheres indígenas, e pelo historiador René De La Pedraja (1984), que indaga sobre a mulher crioula e mestiça na sociedade colonial colombiana. Ali, o matrimônio é, sobretudo, uma regulação social e jurídica na qual a mulher é reduzida econômica, social e politicamente, mas também, paradoxalmente, é retratado como um "privilégio" de status que nem todas as mulheres conseguiam alcançar.

No seu relato sobre o mecanismo dos dotes matrimoniais, De La Pedraja (1984) assinala que, durante o século XVII, nos casos em que as mulheres não possuíam dote, como era o caso das meninas órfãs ou das mulheres dos segmentos mais empobrecidos da sociedade que estavam sob o amparo da caridade, foram destinados recursos doados para sua garantia. No entanto terminaram sendo rejeitados, posto que se iniciaria um processo de transferência de recursos às classes mais indigentes, que, por consequência, poderia alterar a estrutura da sociedade colonial.

Em Bogotá, vale o registro, existiram instituições como a cadeia El Divorcio, fundada em 1784, em que eram jogadas as mulheres que pediam nas ruas, consideradas criminosas-adúlteras, descartáveis por não serem virgens, pois, segundo padrões comportamentais vigentes, essas condutas atentavam contra a moral sexual. Eram levadas para lá, também, mulheres que se encontravam à noite pelas ruas, no exercício da prostituição, processo que se intensifica a partir do século XVIII, atingindo violentamente mulheres indígenas que, com a colonização, migraram aos centros urbanos de recente fundação. Portanto, as famílias instituídas nesses centros atraíam uma grande quantidade de jovens indígenas para trabalhar no serviço doméstico, em regime de escravidão. Muitas dessas jovens eram utilizadas como objeto de prazer pelos homens, donos da casa, elou para iniciação sexual de seus filhos. Uma vez grávidas, eram expulsas, jogadas à própria sorte (SIXIREI, 2013).

Por intermédio do matrimônio e do modelo da família monogâmica e conservadora padronizada pelas elites emergentes, as mulheres mestiças de classe média e alta podiam, até certo ponto, se livrar de outras formas de 
opressão, ao contrário das mulheres indígenas e pretas escravizadas que, na nova organização do espaço da cidade colonial, ficaram expostas a diferentes dinâmicas de abuso e exploração, tanto nos espaços privados instituídos quanto nos públicos - em outros termos, tanto na casa quanto na rua.

Nos fatores de distribuição do território na colonização, não só as mulheres estiveram vetadas, como foi determinante também o critério étnico-racial para o acesso à cidade. As nomeadas "castas" condicionaram a ordem social, restringindo aos desfavorecidos - indígenas, negros, mestiços - o acesso à educação, saúde, aos cargos administrativos nas colônias e nas funções eclesiásticas (FORERO, 2016). Enquanto isso, a formalização da barbárie encontrava justificativa e suporte nos discursos religiosos que classificavam a escravidão e o abandono das "castas inferiores" como formas de correção da suposta maldade natural desses povos.

Em consequência, é possível reconhecer outro sujeito-chave no processo de colonização que configurou a nascente cidade colonial: a religião cristã. Com ela, fortaleceram-se o poder e o controle ideológicos dos colonizadores materializados na construção de igrejas consideradas como importante ponto de encontro das cidades, sendo, ainda, o segmento que mais propriedade privada acumulava. Bogotá, no século XVII, caracterizou-se pela construção de templos, igrejas, monastérios, conventos, produzindo um processo de urbanização marcado pela imposição da tradição religiosa (FORERO, 2016).

A paisagem da cidade implicou, assim, a centralização do poder, representada na Igreja e na influência dos conquistadores - homens brancos -, que, com a construção de obras arquitetônicas na praça e ao seu redor, produziam a legitimidade visual da Bogotá como centro e capital da Real Audiência Espanhola. Essa distribuição inicial foi complementada pelas primeiras definições dos espaços para o comércio e a vida social nos mercados, e outros mais fechados para o desenvolvimento da vida "privada" e familiar.

No entanto o processo de configuração da cidade colonial não foi linear. A exploração do território e da população indigena e negra que marcou a colonização resultou em enfrentamentos entre os espanhóis e os povos nativos, os quais, na tentativa de resistência, foram pouco ao pouco exterminados. $\bigcirc$ saldo da disputa pela terra e pela vida foram populações polarizadas, escravizadas, mulheres estupradas e, até mesmo, pessoas jogadas à mendicância para sobreviver.

Esse percurso permite identificar que a cidade colonial foi um espaço territorial que respondeu a um projeto "civilizatório" de exploração e abuso que, 
dentro da sua divisão racial, econômica e de gênero, produziu condições para uma acumulação emergente tanto em escala local quanto no cenário mundial, ao mesmo tempo em que estimulava a precarização da vida de setores sociais, cuja existência foi determinante dentro desse processo de dominação.

Portanto a precariedade socialmente produzida dos povos indígenas é considerada como o primeiro antecedente de que se tem registros para anunciar o surgimento do fenômeno da população em situação de rua em Bogotá. Mesmo que tenha se transformado e metamorfoseado na contemporaneidade, de modo geral este fenômeno se refere aos sujeitos que, como produto de relações estruturais desiguais, fazem da rua, do ambiente público instituído na divisão social e sexual do espaço da cidade ocidental, o lugar onde resolvem suas necessidades privadas.

Assim, os primeiros sujeitos que, pelas condições de exploração que os atingiam, fizeram esse movimento, ou seja, os primeiros moradores de rua da Bogotá, foram parte das populações indígenas que resistiram à invasão e à imposição da cultura ocidental, despojadas do território, da sua cosmologia, da sua condição humana, até que, ao final, terminaram jogadas às ruas das emergentes cidades coloniais.

Por sua vez, como já assinalado, a cidade colonial implicou na estruturação da propriedade privada, determinante na distribuição do espaço, especialmente entre os lugares específicos da vida pública e aqueles reservados para o privado. Dessa forma, a frágil separação entre a casa e a rua na cidade colonial resultou na emergente diferenciação dos vínculos, das relações, das funções e dos sujeitos "próprios" para cada espaço. Lembrando que, na precarização da vida que se massifica na cidade e os sujeitos que a vivem, é possivel, ademais, situar a realidade das mulheres, para a qual a configuração do espaço urbano esteve também determinada pela divisão sexual do trabalho. Este último processo encontra abrigo na organização econômica e institucional imposta pela colonização em que a figura da família se encontra separada do espaço público, encerrada no contexto da casa, evidenciando que "a família, surgiu no período de acumulação primitiva como a instituição mais importante para a apropriação e para o ocultamento do trabalho das mulheres" (FEDERICI, 2017, p. 193).

No caso da Bogotá, o processo de separação da casa em relação ao espaço público não foi homogêneo. As mulheres indígenas e escravas continuaram submetidas não somente à instituição da família, mas também à ordem social do trabalho como um todo, realizando, por exemplo, 
o trabalho doméstico não apenas de suas familias, mas também exploradas pelas famílias colonizadoras. Portanto as mulheres indígenas e pretas escravizadas na cidade colonial ficaram expostas a diferentes dinâmicas de abuso e exploração tanto nos instituídos espaços privados quanto nos públicos.

Por conseguinte, a realidade da precarização da vida, própria da organização colonial da cidade, atingiu de forma diferenciada as mulheres em relação ao seu status social, cercadas em casa sob a sombra de um homem, fossem elas da elite dos conquistadores ou exploradas e submetidas, no caso das mulheres indígenas e negras. Aquelas que resistiram a ocupar esses lugares - como foi o caso das prostitutas, viúvas, divorciadas ou solteiras pobres - fizeram parte da população denominada à época como "vagabunda" e "mendiga" e, em muitos casos, terminaram errando pelas ruas da cidade.

\section{Da cidade pós-colonial à cidade moderna: os efeitos da dependência na cidade latino-americana}

Ainda que comportem condições históricas específicas, nem todos os países da América Latina tiveram o mesmo destino. Alguns viveram processos de industrialização um pouco mais amadurecidos, como é o caso do Brasil, da Argentina e do México (SINGER, 1998). Em outros, o poder da oligarquia latifundiária gerou outros matizes, como foi o caso da Colômbia. Para compreender essas particularidades, reconhece-se a independência como marco e cenário de mudanças parciais na reconfiguração do espaço. No caso da Colômbia, a sociedade neogranadina encarou uma disputa pelo território e "se viu confrontada por duas forças não só militares, mas também por dois projetos políticos" (FORERO, 2016, p. 75, tradução nossa), produzindo um dualismo constante -federalismo/centralismo - que vai se traduzir em diferentes formas de violência no país e que, paradoxalmente, perpetuaram as relações de dependência.

Tais regimes de centralização e federalismo protagonizaram a disputa pela administração do poder político no processo da independência que, na verdade, almejava a autonomia da colônia, mas não a expulsão total do controle exercido pela coroa. Havia, então, a situação de um modelo colonial dividido com bases sociais fracas, ainda em formação, mediante as tentativas de instaurar um projeto político republicano. Logo, a independência representou para as cidades da América Latina uma autonomia relativa, ainda marcada pela relação de dominação/dependência que determinou o processo de conquista-colonização. 
Na perspectiva de Manuel Castells (1986), as relações de dominação/ dependência na história têm se colocado em três tipologias principais que podem coexistir: dominação colonial (exploração direta dos recursos), dominação capitalista comercial (intercâmbio assimétrico para extrair matérias-primas e mão de obra) e dominação imperialista industrial e financeira (processo de especulação e controle de indústrias locais para tirar vantagens do sistema de substituição de importações). No começo do século XIX, a configuração da cidade de Bogotá apresentava, simultaneamente, relações de dependência de natureza colonial e capitalista comercial.

Por sua vez, a construção de uma taxonomia racial no sistema de castas influenciou significativamente a distribuição do espaço em Bogotá. Desse modo, no século XIX, na cidade, a elite crioula tinha consolidado um estilo de vida europeizado, ao mesmo tempo em que continuava desvalorizando, a partir de um olhar local, as práticas dos povos indígenas que, ainda que tenha sido alvo de perseguição e domesticação sistemáticas durante a conquista/colonização, ainda representavam a maioria da população. Conservavam uma cosmologia de vida afastada da lógica produtiva das relações humanas e do trabalho, perspectiva que, no imaginário das elites crioulas, justificava a falta de ocupação.

Neste cenário também se consolidou a visão pejorativa das camadas mais pobres da sociedade, cujas práticas cotidianas foram associadas ao ócio, e todo aquele que não tivesse uma ocupação ou que estivesse errando pelas ruas foi denominado como "vagabundo" e punido por isso (ROBLEDO GÓMEZ; RODRÍGUEZ SANTANA, 2008), negando-se, assim, a relação causal entre as condições econômicas, sociais e raciais estruturais com a precarização da vida.

Por sua vez, no contexto beligerante da independência, ampliou-se a migração interna aos centros urbanos, sendo Bogotá a cidade com maior índice de crescimento. Segundo o primeiro censo da república, registrado na biblioteca do Departamento Administrativo Nacional de Estadística Dane (1975), em 1825, a região central do país tinha o total de 188.695 habitantes - 90.214 mulheres e 98.481 homens -, dos quais 2.382 foram registrados como escravos (1.275 mulheres e 1.107 homens). Nesse período, inicia-se um crescimento constante da população, produto das migrações, e assim, no ano 1851, incrementou-se para o total de 317 mil habitantes, dos quais 153.303 eram homens e 164.048 mulheres.

$\bigcirc$ processo de migração tem sido uma constante na relação campo-cidade, que se intensifica de forma diferenciada com o projeto de modernização 
da cidade. Reconhecendo, segundo a perspectiva de Castells (1986), que esse movimento nas cidades de América Latina, mais do que produto da expansão da qualidade de vida da urbe é, pelo contrário, consequência da precarização da vida no campo. Isso explica como a figura do latifúndio protagonizou a concentração da terra, impossibilitando a vida no campo, ao ponto de empurrar camponeses e indigenas a se deslocarem para a cidade que, por sua vez, não tinha a capacidade territorial nem de serviços para acolher essa população.

Essa precarização rural é retratada pelo sociólogo Orlando Fals Borda (2015) no seu trabalho sobre a história da questão agrária na Colômbia, realizando um percurso sobre as mudanças que caracterizaram a luta pela terra e que produziram a "decomposição do campo". Interessa aqui destacar que, no século XIX, implementaram-se as primeiras legislações (1821, 1832 e 1843) que, no discurso do liberalismo, pretendiam modernizar a vida rural eliminando, por exemplo, a figura do resguardo indigena ${ }^{3}$ que, mesmo sendo de origem colonial, procurava garantir, com autonomia relativa, o acesso da população indígena a parcelas de terra; medida que, ao final, acabou por favorecer a figura do latifúndio.

crescimento da cidade se constituiu como extensão da luta pela terra que marca transversalmente a história do país. Em relação ao espaço urbano, produziu-se a expansão de bairros periféricos e também a presença de populações migrantes que passam a ocupar o centro e lugares de comércio, registrando-se, aí, os chamados mendigos ou gamines. Nesse processo, é preciso destacar que a migração sobrevinha principalmente das mulheres camponesas e indigenas, em particular porque, com os confrontos pela independência e as constantes disputas territoriais no campo, muitas delas fugiam da violência ou ficavam desamparadas, viúvas ou órfãs (FORERO, 2016).

Considerando que a independência representou mais a substituição de sujeitos do que mudanças significativas nas relações de poder, destaca-se que as estruturas de dominação estabelecidas com a colonização persistiram ainda no século XIX. Embora estivessem contidas nessas estruturas matizes influenciadas, no caso da questão racial pelo processo de mestiçagem e na divisão social do trabalho pelo processo migratório, as relações de poder baseadas no sexo, por sua vez, mantiveram e até radicalizaram a subordinação das mulheres, aprofundando a divisão sexual do trabalho e reproduzindo visões divididas da condição do ser mulher, imersas na relação público/privado-rua/casa.

3 Parcelas de terra delimitadas e asseguradas pelos colonizadores a alguns sobreviventes das populações indígenas que lutaram pelo acesso a terra e contra a figura da propriedade privada que se expandiu pelo território. 
Há que se demarcar que as estruturas de dominação de classe e de gênero e a sua materialidade na cidade não agem separadamente. Essa relação é abordada pelo feminismo materialista na perspectiva da divisão sexual do trabalho e suas implicações sobre os lugares que ocupa cada sujeito nas relações sociais de produção, as quais, em diálogo com os parâmetros da industrialização, foram fundamentais na construção da cidade moderna. Segundo essa perspectiva, com a divisão sexual do trabalho, aparece o binarismo produção/reprodução, que "tem como características a designação prioritária dos homens à esfera produtiva e das mulheres à esfera reprodutiva e, simultaneamente, a apropriação pelos homens das funções com maior valor social adicionado (políticos, religiosos, militares etc.)" (HIRATA; KERGOAT, 2007, p. 599).

A partir desta análise, enquanto as atividades associadas à produção adquirem valor no espaço público e na ocupação das ruas, aquelas que atingem a reprodução parecem ser exclusivas do âmbito privado da casa, colocando a sexualidade em função dos interesses do capital e exigindo das mulheres práticas de cuidado desvalorizadas, insistindo em que essa distribuição foi mais complexa ainda no caso das mulheres indígenas, mestiças e negras.

Assim, como assinala Suzy Bermúdez (1993), mesmo que exista pouca informação sobre a realidade pretérita das mulheres em Bogotá e a existente esteja permeada pelo olhar masculino da história oficial, sabe-se que o século XIX se caracterizou pela visão binária das mulheres, que as dividia entre a mulher sagrada e a mulher prazer. A primeira, legitimada no ainda influente discurso religioso, seguia com devoção os referenciais da virgem-mãe, a segunda, por sua vez, as profanava; enfrentando as ações punitivas que evidenciaram a cumplicidade estatal a esse modelo, tanto na sua perspectiva conservadora quanto na sua aparência liberal.

Mas há aqui um elemento a se destacar para cada um desses arquétipos. A mulher sagrada e a mulher prazer dialogavam com a posição social da mulher e com o seu lugar dentro da divisão do espaço na cidade. Logo, a mulher sagrada era, no geral, representada pelas mulheres brancas das elites sociais que ocupavam o espaço privado - a casa; a mulher prazer, no caso, "referia-se em particular à população feminina que não pertencia à condição social nem étnica dos grupos dirigentes" (BERMÚDEZ, 1993, p. 36, tradução nossa), cuja vida se desenvolvia especialmente nos espaços vedados ao público. Em resumo, sobre estas mulheres, além da demarcação racial no sistema de castas, foi imposta também a divisão sexual do trabalho não somente em relação aos homens, mas também na distribuição do trabalho das mulheres entre si. 
Contudo há perspectivas de análises históricas que desconhecem essa realidade ou a negam, afirmando que esse período foi apenas transitório na intersecção raça e classe, pois substituiu-se o sistema de castas pelas diferenciações econômicas entre ricos e pobres. Em outras palavras, a prioridade era o "ordenador centrado na riqueza e nas condições de produtividade - ricos, empregados, profissionais, obreiros e um amplo número de pobres e miseráveis que deambulavam pelas ruas" (ROBLEDO GÓMEZ; RODRÍGUEZ SANTANA, 2008, p. 85, tradução nossa).

Certamente, mesmo com todos os esforços pela industrialização e modernização impostos à cidade de Bogotá que caracterizaram o século $\mathrm{XIX}$, as relações de classe em termos da industrialização da cidade foram precárias e, ainda que se considere que o ordenador da riqueza fosse a propriedade privada, o acesso a ela continuou cumprindo os critérios de raça e sexo da cidade colonial: homens brancos.

Aliás, a configuração da luta de classes na Colômbia foi um processo de idas e vindas entre a vida rural e urbana, levando em conta que o desenvolvimento das primeiras indústrias acontece, principalmente, no final do século XIX. Em consequência, a falta de infraestrutura da cidade nesse período diante do aumento da população, produto das migrações internas, resultou em condições de superlotação que contrariavam também os discursos de salubridade e higiene, fundamentais no pretendido projeto estético da modernização.

A essa reflexão, apoiando-se na teoria social crítica, acrescenta-se que a dependência/dominação como tem se demonstrado neste texto está demarcada no contexto da divisão internacional do trabalho, que faz que não seja produto de uma condição de "atraso", e sim de uma participação em si mesma marginal no interior de uma totalidade que se sustenta dessas condições.

A marginalidade urbana na América Latina se refere, aqui, à formações sociais causadas no interior das contradições próprias das relações de produção/exploração que, baseadas na acumulação do capital, criam, justificam e sustentam condições de vida precárias de uma parte significativa da população, materializadas na imposição de lugares diferenciados na cidade segundo critérios de raça, sexo e classe. Assim, a partir de relações de exploração diretas e indiretas, nega-se o direito à cidade, por meio de uma participação em si mesma marginal. 


\section{A cidade moderna? Consolidação do recorte de classe na marginalidade urbana de Bogotá}

O projeto de modernização, que até o século XIX tinha se colocado na disputa pelo poder político administrativo do país, começa a tomar forma no século XX, especialmente em mão das elites sociais que promoveram o liberalismo. Assim, após a Guerra dos Mil Dias (1899-1902), que deixou como saldo incrementos na dívida externa, a cidade de Bogotá foi alvo de diversas modificações.

Na primeira metade do século XX, com o horizonte a massificar a produção agrícola, estimulou-se o sistema de transporte ferroviário por meio do qual se pretendia, igualmente, aumentar a circulação comercial do centro ao interior e ao litoral do país. A ação visava a fortalecer a relação industrialização-urbanização das cidades. Processos que atingem realidades diferentes nos países da América Latina, por exemplo, o desenvolvimento da estrutura de transporte desenvolvido na Colômbia e que sustentou o projeto de urbanização de Bogotá como sua capital, foi significativamente mais pausado em comparação com o Chile ou a Argentina, que, nos anos 1920, já tinham uma ampla rede de transporte (TORRES DEL RIO, 2010).

No contexto de expansão do território urbano, a Colômbia toda passava por mudanças sociais tanto nas cidades quanto nos campos. Em Bogotá, foi aumentando o número de bairros operários, produto da massificação das migrações internas motivadas pelas violências que se agudizavam no campo, mas também pelo processo inicial de industrialização da cidade.

Em suma, interessa ressaltar que esses bairros operários que, na época, cercaram o centro da cidade foram ocupados por população majoritariamente migrante, especialmente famílias camponesas, indigenas, obreiras e ainda mais mulheres, que, no contexto da luta pela terra - como assinala Donny Meertens (1997) no seu estudo sobre as mulheres na história rural da Colômbia no século XX - estiveram condicionadas pela divisão sexual do trabalho no interior das fazendas ou na estrutura familiar camponesa, tendo uma restrita, mas não nula ${ }^{4}$, participação nas ações dos movimentos rurais e alguns levantes urbanos. E foram, também, em muitos casos, obrigadas a abandonar seu território e se aventurar na cidade, desempenhando labores domésticos ou atividades ligadas à prostituição.

4 Destacam-se as lideranças de mulheres como Maria Cano na fundação do Partido Revolucionário Socialista e Betsabé Espinoza, como líder obreira da greve de Bello de 1920. 
Sobre o lugar das mulheres na sociedade camponesa do século XX na Colômbia, Meertens (1997) apresenta reflexões em torno das relações de violência particulares que as atingiram nesse contexto, fazendo acento na violência sexual exercida sistematicamente contra elas como instrumento de repressão do movimento camponês e indigena em sua totalidade. Assim, "tal era a preocupação, que a questão do acesso sexual às mulheres entrava nas negociações e arranjos laborais das Ligas Campesinas da região com os fazendeiros e o ministério do trabalho" (MEERTENS, 1997, p. 77, tradução nossa).

Em decorrência do processo migratório, o crescimento da cidade esteve acompanhado da configuração de núcleos da classe trabalhadora, portanto é no limiar do ano de 1918 que registram-se as primeiras ações do "proletariado urbano" em Bogotá. A rua - o espaço de trânsito público que ampliava e conectava a cidade moderna e que na cidade colonial e na cidade republicana tinha sido ocupada principalmente por ações religiosas e militares - começava a ser cenário explícito de lutas e reivindicações sociais.

Tais mudanças no uso do espaço respondiam à marginalização da vida. A população migrante foi ocupando áreas periféricas em relação ao centro e ao norte da cidade. Essa região foi o rumo para onde se movimentaram as elites sociais em sua tentativa de manter a segregação do espaço urbano, em que o direito à cidade e sua institucionalidade em matéria de saúde, higiene e educação variavam conforme o lugar de residência. Contudo, mesmo que se reconheça a iniciante formação do proletariado urbano, os processos mais representativos de mobilização dos trabalhadores da primeira metade do século XX se deram especialmente no setor industrial das áreas rurais do interior e litoral do país: Ciénaga (Magdalena), com o acontecimento conhecido como massacre das bananeiras, e em Líbano (Tolima), com a insurreição dos bolcheviques, evidenciando a predominância do proletariado rural.

Até os anos 1930, o regime conservador manteve o poder com sutis concessões ao projeto moderno, sempre resguardando a organização das relações tradicionais que implicaram perpetuar a figura do latifúndio, os valores da familia e a devoção na Igreja. É especialmente a partir da terceira década do século XX, diante da pressão do contexto internacional (cenário pós-Primeira Guerra Mundial, Crise de 1929 e missão Kemmerer ${ }^{5}$ ) que se encara

\footnotetext{
5 Registrada como a abertura da economia colombiana aos interesses estadunidenses que, após a Primeira Guerra Mundial, havia se instituido como o referente de modernização no continente americano. A missão Kemmerer consistiu na visita e no estudo das condições econômicas e da capacidade de endividamento do país para adquirir empréstimos estrangeiros; processo que também foi implementado no Peru, Chile, Equador e na Bolivia, em que, tendo a modernização como objetivo, estimulou o controle econômico estrangeiro (DRAKE, 1984) e a perda de autonomia dos governos locais da América Latina, com a divida externa como indicador.
} 
diretamente a incipiente modernização com o fortalecimento do setor industrial, mas, na cidade de Bogotá, sua implementação não foi o resultado

[...] de um processo de industrialização do qual se deriva uma economia urbana, como é o caso do capitalismo clássico, senão como resultado da economia exportadora cafeeira, condição que geraria uma modernização urbana muito específica. A via da nossa modernização se deu a partir de uma economia agrária, que não precisou se modernizar completamente e, portanto, com forte presença do mundo tradicional. (ROBLEDO GÓMEZ; RODRÍGUEZ SANTANA, 2008, p. 220, tradução nossa).

Interessa retomar essas categorias, porque o século $X X$ é considerado o momento em que a cidade de Bogotá consolida o projeto da modernização por meio das primeiras iniciativas de industrialização, tendo os Estados Unidos, nova potência industrial, como referência. E porque é importante, também, identificar até que ponto os relatos construídos sobre a luta de classe nesses territórios atingem a realidade dessa cidade da América Latina que, como já apontado, ocupa um lugar específico na divisão internacional do trabalho.

Importa ainda mais refletir sobre as características da superpopulação relativa no contexto da cidade de Bogotá, já que nesse excedente encontram-se condições de vida pauperizadas nas quais viveram o proletariado urbano emergente e a população em situação de rua, que, exatamente a partir desse período, expande sua presença na cidade. É justamente numa parte significativa dos primeiros bairros operários que atualmente se concentra o fenômeno da população em situação de rua em Bogotá.

Segundo Romero (1976), o século XX em Bogotá foi atravessado por processos migratórios internos não motivados pela ascensão social de famílias latifundiárias como acontecera com maior força na segunda metade do século XIX e, sim, por pessoas empobrecidas, provenientes do campo e de cidades pequenas.

Logo, a marginalidade urbana é própria da morfologia social da centralização e "modernização" das relações sociais materializadas na produção do espaço da cidade, processo que, no começo, foi justificado no projeto civilizador e que, no século $X X$, muda sua nomeação para desenvolvimento. Contudo a população em situação de rua se constitui como fenômeno propriamente urbano, pois faz parte das manifestações sociais das contradições próprias dessa imposição.

Na primeira metade do século $X X$, estruturaram-se as bases da distribuição da cidade contemporânea. A partir disso, as particularidades do 
contexto latino-americano na configuração da divisão espacial da cidade estão representadas na relação contraditória de caos e ordem que atravessa suas periferias, que, como assinala Wallerstein (2004 apud ZIBECHI, 2007, p. 185, tradução nossa), "Nos subúrbios confluem algumas das mais importantes fraturas que atravessam o capitalismo: raça, classe, etnia e gênero. São os territórios da desapropriação quase absoluta".

Essa pauperização extrema da vida compõe uma totalidade na qual nenhum fenômeno se apresenta puramente teórico. Desta feita, os postulados que descrevem o processo de modernização como um todo, a partir do olhar específico da sociedade hegemônica ocidental, enfrentam o desafio da diversidade histórica e social dos contextos periféricos, no interior deles, a configuração da cidade latino-americana na qual coexistem formações sociais de exploração coloniais, comerciais e modernas num mesmo espaço-tempo.

\section{Considerações finais}

Com a heterogeneidade histórica do fenômeno e os matizes que este adquire em cada fase da cidade, não é possivel estabelecer um perfil homogêneo da população em situação de rua, mas sim aproximar algumas generalidades da sua configuração, que, como acontece com a cidade de Bogotá, em que coexistem diferentes tipos de espaço entre o colonial e o moderno, no fenômeno da população em situação de rua também convivem múltiplas realidades e formas de habitar a rua.

$\bigcirc$ tratamento histórico conferido ao fenômeno permitiu compreender, em termos interseccionais, as disputas que atravessam a realidade dessa população, começando pela relação de exploração e resistência colonizadores/colonizados, em que se destaca que o fato de serem, em parte, provenientes de comunidades indigenas os relega a condições marginais no interior da frágil cidade colonial. Passando também pelo processo de mestiçagem, que coloca no centro da disputa territorial a questão étnico/racial e se consolidam aos poucos as elites locais que, na escusa da independência, manterão a precarização das "raças inferiorizadas", perpetuando as pautas estabelecidas com respeito à população indígena, agora na cidade pós-colonial.

Esse cenário de contendas foi chave também na cidade republicana, onde, além de se desenharem as bases institucionais que organizaram a cidade, se estabeleceram relações de exploração/resistência marcadas por um confronto direto pela propriedade da terra, em que a relação de contradições campo-cidade deixa um saldo importante de pessoas marginalizadas. 
Assim, finalmente se consolidam os traços da população em situação de rua da cidade moderna, marcada pela luta agrária que tem protagonizado as disputas sociais na América Latina. Em um contexto de conflito armado e o subjacente deslocamento forçado, que faz que a cidade de Bogotá cresça mais do que tem capacidade territorial de conter; fazendo, aliás, que, na lógica contraditória que define a sociedade capitalista, da mesma forma em que se produz riqueza, se produza uma superpopulação excedente, integrada também pela população em situação de rua.

Identifica-se até aqui que pessoas que fazem da rua o espaço onde residem e desenvolvem sua vida cotidiana, como resultado de dinâmicas de desigualdade estrutural na busca por sobreviver, têm existido desde a configuração da cidade ocidental e se encontram envoltas nas relações de exploração que as caracterizam, ocupando sempre um lugar marginalizado, não porque não participem das relações sociais de produção, senão porque sua participação é precária e disfuncional. Assim, ao contar a história da cidade desde os "polos" que a disputam, se reconhece que essa população está posta nos extremos explorados e marginais da relação: quem vive na rua como produto de determinações estruturais não é o homem branco, burguês.

A pobreza e a desigualdade, próprias da cidade no interior do capitalismo e, mais ainda, no sul global, em que se inferem outras variáveis produzidas na relação colonial, não só estão atravessadas por condições de classe, como se buscou reforçar nestes escritos, mas também são atingidas pelos recortes de gênero e étnico-racial. Isso leva à necessidade de, ao analisar a configuração do espaço num olhar mais abrangente, identificar os vínculos entre a questão social, sexual e racial, e de entender como eles aparecem nas fronteiras, situadas como incógnita nos lugares cooptados pelas relações de dominação hegemônicas.

Nesse contexto, buscou-se colocar a realidade também das mulheres moradoras de rua na história, reconhecendo a dificuldade de ser uma história contada sobre um espaço marginalizado e masculinizado da vivência na rua, a partir de uma perspectiva também majoritariamente masculina. $\bigcirc$ desafio agora é entender o que acontece com relações específicas de gênero nesse espaço, à luz das análises que, a partir de uma leitura binária imposta, tem posicionado as mulheres no lugar precário dessa disputa. Análises que, espera-se, sejam desenvolvidas por outros estudos. 


\section{Referências}

BERMÚDEZ, S. El bello sexo: la mujer y la familia durante el Olimpo Radical. Bogotá: Universidad de Los Andes, 1993.

CASTELLS, M. La cuestión urbana. Barcelona: Siglo XXI, 1986.

CRENSHAW, K. Documento para o encontro de especialistas em aspectos da discriminação racial relativos ao gênero. Revista Estudos Feministas, Florianópolis, n. 1, p. 171-188, 2002. Disponivel em: https://bit.ly/3gJVn94. Acesso em: 28 jan. 2020.

DE LA PEDRAJA, R. La mujer criolla y mestiza en la sociedad colonial, 1700-1830. Revista Desarrollo y Sociedad, Bogotá, n. 13, p. 199-229, 1984.

DEPARTAMENTO ADMINISTRATIVO NACIONAL DE ESTADÍSTICA. Estadísticas históricas. Bogotá, 1975. Disponivel em: https://bit.ly/2ALue6f. Acesso em: 22 mar. 2020.

DRAKE, W. P. La misión Kemmerer a Chile: consejeros norteamericanos, estabilización y endeudamiento, 1925-1932. Cuadernos de Historia, Santiago de Chile, n. 4, p. 31-59, 1984.

FALS BORBA, O. Una sociología sentipensante para América Latina. Ciudad de México, DF: Siglo XXI, 2015.

FEDERICI, S. Calibã e a bruxa: mulheres, corpo e acumulação primitiva. São Paulo: Elefante, 2017.

FORERO, P. M. Breve historia de Bogotá. Bogotá: Planeta Colombiana, 2016.

HIRATA, H.; KERGOAT, D. Novas configurações da divisão sexual do trabalho. Cadernos de Pesquisa, São Paulo, v. 37, n. 132, p. 595-609, 2007.

LEFEBVRE, H. El derecho a la ciudad. Barcelona: Península, 1978.

MELO, M. V. La calle: espacio geográfico y vivencia urbana en Santa Fe de Bogotá. Bogotá: Alcaldía Mayor de Bogotá, 2001.

MEERTENS, D. Tierra, violencia y género: hombres y mujeres en la historia rural de Colombia, 1930-1990. Nimega: Universidad Radboud de Nimega, 1997. 
PATEMAN, C. O contrato sexual. São Paulo: Paz e Terra, 1993.

RÍPODAS, D. El matrimonio en Indias: realidad social y regulación jurídica. Buenos Aires: Fundación para la Educación, la Ciencia y la Cultura, 1977.

ROBLEDO GÓMEZ, A. M.; RODRÍGUEZ SANTANA, P. Emergencia del sujeto excluido: aproximación genealógica a la no-ciudad en Bogotá. Bogotá: Pontificia Universidad Javeriana, 2008.

ROMERO, J. L. Latinoamérica: las ciudades y las ideas. Buenos Aires: Siglo Veintiuno, 1976.

SINGER, P. Economia política da urbanização. São Paulo: Contexto, 1998.

SIXIREI, C. Sexualidad, razas impuras y control religioso en la Colombia Colonial. Revista Psicología Política, São Paulo, v. 13, n. 26, p. 25-36, 2013.

TORRES DEL RIO, C. Colombia siglo XX: desde la guerra de los mil días hasta la elección de Álvaro Uribe. Bogotá: Pontificia Universidad Javeriana, 2010.

ZIBECHI, R. Autonomías y emancipaciones: América Latina en movimiento. Lima: Universidad Nacional Mayor de San Marcos, 2007.

Recebido em abril de 2020.

Aprovado em junho de 2020. 